\title{
Highly accelerated single breath-hold non- contrast thoracic MRA: evaluation in a clinical population
}

\author{
Ruth P Lim ${ }^{2,1^{*}}$, Priscilla A Winchester ${ }^{2}$, Mary T Bruno ${ }^{2}$, Jian Xu ${ }^{3}$, Pippa Storey ${ }^{2}$, KellyAnne McGorty ${ }^{2}$, \\ Daniel K Sodickson ${ }^{2}$, Monvadi B Srichai ${ }^{2}$ \\ From 16th Annual SCMR Scientific Sessions \\ San Francisco, CA, USA. 31 January - 3 February 2013
}

\section{Background}

Gadolinium enhanced MRA (Gd-MRA) is commonly used in clinical practice for evaluation of the thoracic aorta. Electrocardiographic (ECG) gating is required for accurate aortic root assessment, but decreases scanning efficiency. We evaluate the performance of a highly accelerated, breath-hold 3D ECG-gated non-contrast enhanced steady state free precession MRA technique (NC-MRA) in a clinical population, compared with ECGgated Gd-MRA.

\section{Methods}

30 patients (22 male, mean age 53.4 years) with known or suspected thoracic aortic pathology were imaged with NC-MRA followed by Gd-MRA at $1.5 \mathrm{~T}$ following informed consent. Images were anonymized and reviewed by 2 readers for aortic pathology. Diagnostic confidence, image quality and artifacts were evaluated on a 5-point Likert scale ( 1 =worst, $5=$ best), with image quality and artifacts evaluated segmentally in 10 vascular segments, including the sinuses of Valsalva and coronary artery origins. Aortic dimensions were measured in 7 aortic segments. Diagnostic confidence, image quality and artefact scores were evaluated with the Wilcoxon signed rank test. Paired Student $\mathrm{t}$-test and Bland-Altman analysis were used for comparison of aortic dimensions.

\section{Results}

All patients successfully completed NC-MRA and Gd-MRA (Figure 1). NC-MRA vascular pathology findings were concordant with Gd-MRA in 29/30 (96.7\%)

\footnotetext{
${ }^{2}$ Radiology, NYU Langone Medical Center, New York, NY, USA Full list of author information is available at the end of the article
}

and 28/30 (93.3\%) of patients for Readers 1 and 2 respectively with high diagnostic confidence (mean 4.35 \pm 0.77 ), not significantly different from Gd-MRA (4.38 $\pm 0.64), p=0.74$. Image quality and artefact scores were comparable with Gd-MRA in the majority of vascular segments. Differences were observed at the ascending aorta, where NC-MRA image quality $(3.80 \pm 0.88)$ was inferior to Gd-MRA (4.13 \pm 0.73$)$, and at the coronary artery origins, where NC-MRA was considered superior for the left main $(3.38 \pm 1.47$ versus Gd-MRA $2.78 \pm 1.21)$ and the right coronary $(3.55 \pm 1.40$ versus $2.32 \pm 1.16)$ arteries, $\mathrm{p}<0.05$ for both comparisons. Aortic dimensions were comparable, with only one significant difference observed at the ascending aorta, where mean NC-MRA dimension $(4.05 \pm 0.76 \mathrm{~cm})$ was less than $1 \mathrm{~mm}$ smaller than Gd-MRA (4.12 \pm 0.70$), \mathrm{p}=0.043$.

\section{Conclusions}

Breath-hold non-contrast enhanced MRA of the thoracic aorta yields good image quality, comparable to ECG-gated gadolinium-enhanced MRA, with high accuracy for aortic dimensions and pathology. It can be considered an alternative to gadolinium-enhanced MRA in patients with relative contra-indications to gadolinium contrast or problematic venous access.

\section{Funding}

This project was supported by grant number $\mathrm{K} 12 \mathrm{H}$ S019473 from the Agency for Healthcare Research and Quality. The content is solely the responsibility of the authors and does not necessarily represent the official views of the Agency for Healthcare Research and Quality. D.K.S. and J.X. receive grant support from National 


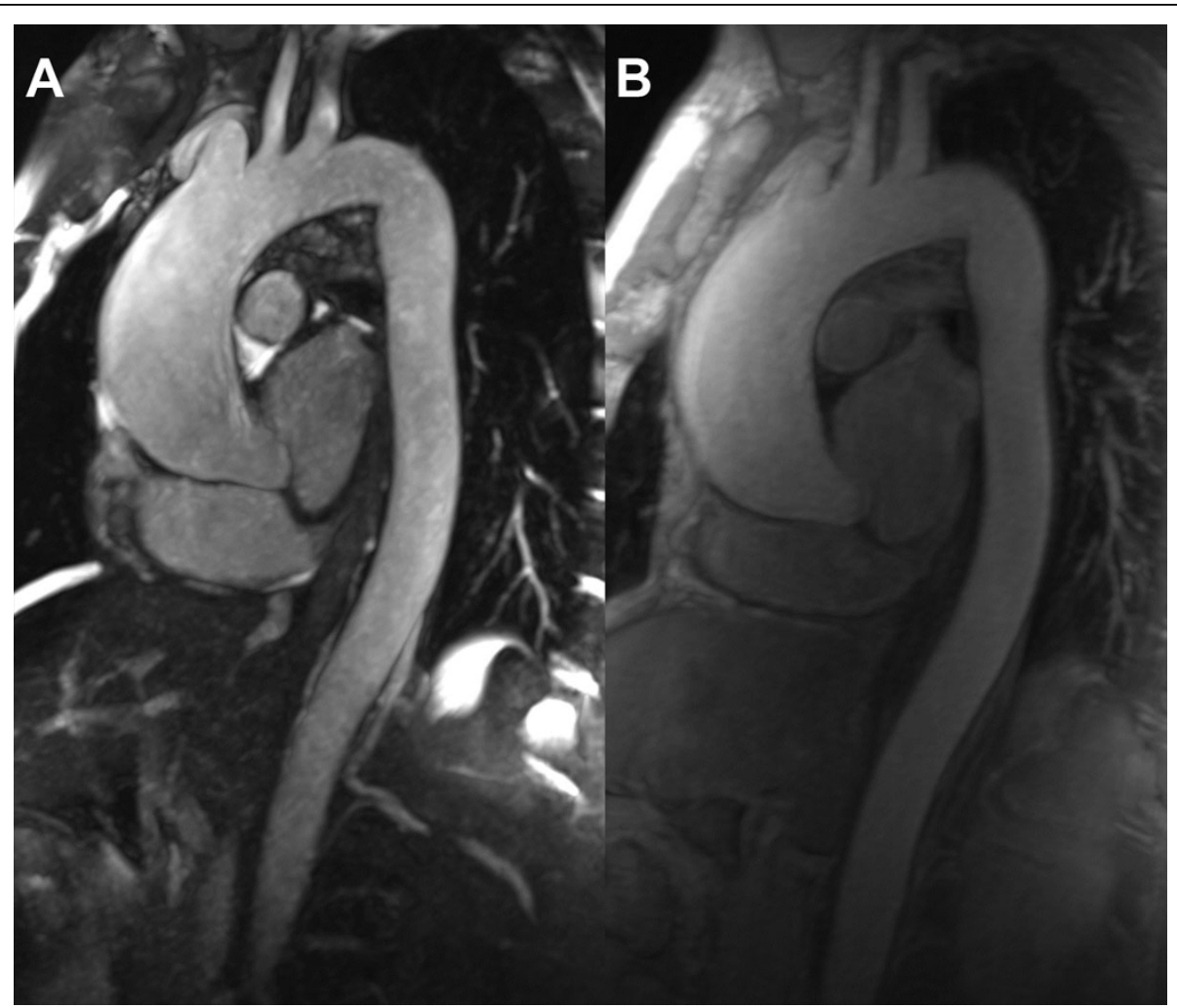

Figure 1 A) Non-contrast and B) gadolinium-enhanced MRA thin MIP images of a 42-year-old male with history of bicuspid aortic valve. The ascending aorta is aneurysmal, measuring up to $4.6 \mathrm{~cm}$, and is well depicted with the non-contrast MRA technique.

Institutes of Health R01-DK069373. J.X. is an employee of Siemens Medical Solutions.

\section{Author details}

${ }^{1}$ Radiology, Austin Health, Heidelberg, VIC, Australia. ${ }^{2}$ Radiology, NYU

Langone Medical Center, New York, NY, USA. ${ }^{3}$ Research and Development,

Siemens Medical Solutions, New York, NY, USA.

Published: 30 January 2013

doi:10.1186/1532-429X-15-S1-E84

Cite this article as: Lim et al:: Highly accelerated single breath-hold

non-contrast thoracic MRA: evaluation in a clinical population. Journal of Cardiovascular Magnetic Resonance 2013 15(Suppl 1):E84.

\section{Submit your next manuscript to BioMed Central and take full advantage of:}

- Convenient online submission

- Thorough peer review

- No space constraints or color figure charges

- Immediate publication on acceptance

- Inclusion in PubMed, CAS, Scopus and Google Scholar

- Research which is freely available for redistribution 